\title{
Dendritic cell ontogeny as an aetiological factor in respiratory tract diseases in early life
}

\author{
P G Holt
}

Large populations of dendritic cells (DCs) are found throughout the respiratory tract, the most prominent comprising a contiguous network dispersed throughout the epithelium and underlying mucosa of the conducting airways. Most of the available information on these cells comes from studies on tissues from experimental animals; however, comparable networks of DCs have also been formally demonstrated in humans. ${ }^{1-3}$

These populations of DCs in the lung and airway wall are now known to play a central role in the maintenance of immunological homeostasis in the respiratory tract (reviewed by Holt and Stumbles ${ }^{1}$ ). As the principal resident antigen presenting cells (APC) in these tissues under steady state conditions, they serve as the local "gatekeepers" of the immune system. The principal function of these DCs is surveillance for incoming (inhaled) antigens deposited on airway mucosal surfaces, which they sample principally via receptor mediated endocytosis. ${ }^{4}$ Resident airway cells perform this function avidly but are relatively inefficient in presenting these antigens to $\mathrm{T}$ cells, due principally to poor surface expression of co-stimulator molecules such as CD80/CD86 which are obligatory second signals for $\mathrm{T}$ cell activation. Maturation of DCs from antigen acquirers into antigen presenters normally does not occur until the cells emigrate from peripheral tissues (bearing the antigens they have acquired) into the $\mathrm{T}$ cell zones of regional lymph nodes. ${ }^{5}$ During or immediately after this migration they mature under the influence of a variety of different cytokines including interleukin (IL)-1, tumour necrosis factor (TNF) $\alpha$, and IL-4, but in particular granulocyte-macrophage colony stimulating factor (GM-CSF) which appears to serve as the "master regulator" in this process. ${ }^{5}$ This functional maturation is readily observable in vitro by culturing respiratory tract DCs in GM-CSF, which induces cycling of intracellular MHC class II complexed with bound antigenic peptide(s) from intracellular vesicles onto the cell surface, and also induces concomitant surface expression of high levels of costimulator molecules. ${ }^{4}$

This strict compartmentalisation of the functions of DCs is believed to play an important role in protecting delicate airway tissues from damage resulting from unwarranted local $\mathrm{T}$ cell activation, a process which inevitably results in release of potentially toxic cytokines. Instead, these activation events are usually restricted to lymph nodes and result in expansion of relevant clones of $\mathrm{T}$ memory cells which subsequently recirculate back into the airway tissues.

An increasing body of indirect evidence suggests that precocious maturation of the APC functions of DCs prior to their migration to draining lymph nodes may be an important factor in the pathogenesis of immunoinflammatory respiratory diseases such as atopic asthma. A hallmark of this disease is the presence of unusually high numbers of activated $\mathrm{T}$ cells in the airway mucosa, ${ }^{6}$ signifying the local presence of active APC. GM-CSF, the principal stimulant for maturation of DCs, is produced at high levels in the airway mucosa of asthmatic subjects ${ }^{7}$ and several studies in patients with asthma (reviewed by Holt and Stumbles ${ }^{1}$ ) report increased numbers of DCs expressing activation markers in these tissues.

Information from experimental models suggests that the DC mediated immune surveillance process is highly efficient in immunocompetent adult animals. Under steady state conditions, populations of DCs in the airway wall are renewed every $36-38$ hours $^{8}$ as antigen bearing DCs migrate to draining lymph nodes and are replaced by incoming immature bone marrow derived DC precursors. However, in the face of local challenge with inert antigens, allergens and, in particular, microbial pathogens, the pace of this sampling process further accelerates to maximise the efficiency of transmission of antigenic "danger" signals to the central immune system. ${ }^{1}$ The highly dynamic nature of this DC sampling process is virtually unique to the conducting airways, underscoring the central importance of the local DC network in immunological protection of these delicate tissues.

Recent studies ${ }^{4}$ indicate that, as well as regulating the overall intensity of the adaptive immune response to local antigen challenge, signals from respiratory tract DCs determine the balance which ultimately develops between the Th1 and Th2 components of immunological memory against inhaled antigens. It is now evident that the default function of resting airway DCs is to prime selectively the naive immune system for expression of Th2 polarised immunity. Furthermore, their capacity to promote alternate Th1 polarised immunity, which is required for protection against both infection and against allergic sensitisation to inhalants, relies absolutely upon their receipt of appropriate stimulatory signals from GM-CSF in conjunction with $\mathrm{TNF} \alpha, \mathrm{IL}-1$, or CD40 ligand.

Thus, in adult animals, respiratory tract DCs appear to orchestrate both quantitative and qualitative aspects of local host immune defence. However, it is equally evident that, at least in experimental animal species, the situation is markedly different in the key period between birth and weaning. Studies principally in the $\mathrm{rat}^{9}{ }^{10}$ indicate that, at birth, DCs are present in only very small numbers in the airway wall and, moreover, express only low levels of surface MHC class II. The explosive in vivo response of the airway DC network to local challenge with inflammatory stimuli is severely attenuated during infancy and, in addition, their capacity to respond in vitro to "maturation" signals from GM-CSF is blunted, which suggests that they may be under some form of active suppression within this microenvironment during early life. 
These findings, if applicable to humans, provide a plausible explanation for both the increased susceptibility of infants to respiratory viral infections and may also explain the low efficiency (relative to adults) of development of $\mathrm{T}$ cell memory to viral infections during this life phase. Additionally, they point to potentially important new areas for research in relation to the aetiology of atopic asthma, including expression of persistent disease in later life.

In this latter context, it is becoming clear that the development of long term immunological memory against the inhalant allergens, which are major trigger factors for atopic asthma in later life, occurs during the early postnatal period (reviewed by Holt et $a l^{11}$ ). Furthermore, protection against allergic sensitisation in the form of development of stable Th2 polarised immunological memory requires allergen specific signalling to the $T$ cell system in a format which selectively promotes Th1 immunity. Given, firstly, that the portal of entry of the relevant (inhalant) allergens is via the respiratory tract and, secondly, that the only APC present to acquire and transmit these allergenic signals to the $\mathrm{T}$ cell system are respiratory tract DCs, it is highly likely that the kinetics of postnatal maturation of this DC network is a rate limiting factor in the development of quantitative and qualitative aspects of $\mathrm{T}$ cell immunity to these allergens.

In the current issue of Thorax, Tschernig and colleagues $^{12}$ provide the first tentative evidence that the ontogeny of respiratory tract DCs in humans may follow a similar pattern to that observed in animal models. They report that dendritiform cells expressing either HLA-DR or CD1 a are rare within the airway mucosa of infants under 1 year of age who died of SIDS or acute trauma. In contrast, HLA-DR+ DC-like cells were present in airway sections from infants who died of respiratory infection and from older children who died from acute trauma.

This preliminary study requires confirmation including, in particular, more detailed characterisation of the surface phenotype of the putative DCs and further sampling during the preweaning period in order to obtain information relating to the kinetics of the developmental process. However, taken together with earlier findings indicating a general paucity of HLA-DR expression in the human airway mucosa during early infancy, ${ }^{13}$ it suggests that, analogous to experimental animals, human respiratory tract DC networks develop almost entirely postnatally.
It is also of interest to note the increased frequency of putative DCs in airway tissues in association with respiratory infection. ${ }^{12}$ This observation is consistent with the results of animal model studies which suggest that the postnatal maturation of respiratory tract DC networks may be "driven" by direct stimulation from inhaled irritant stimuli, including that derived from microbial sources. ${ }^{9}{ }^{10}$ Such a mechanism provides one potential avenue for the "bystander" effects of respiratory infections on the postnatal development of $\mathrm{T}$ cell immunity to other classes of airborne antigens, including inhalant allergens. ${ }^{14}$

P G HOLT

Division of Cell Biology,

TVW Telethon Institute for Child Health Research,

PO Box 855, West Perth,

WA 6872, Australia

patrick@ichr.uwa.edu.au

1 Holt PG, Stumbles PA. Regulation of immunological homeostasis in peripheral tissues by dendritic cells: the respiratory tract as a paradigm. $\mathcal{F}$ Allergy Clin Immunol 2000;105:421-9.

2 Holt PG, Schon-Hegrad MA, Phillips MJ, et al. Ia-positive dendritic cells form a tightly meshed network within the human airway epithelium. Clin Exp Allergy 1989;19:597-601.

3 Cochand L, Isler P, Songeon F, et al. Human lung dendritic cells have an immature phenotype with efficient mannose receptors. Am f Respir Cell Mol Biol 1999;21:547-54.

4 Stumbles PA, Thomas JA, Pimm CL, et al. Resting respiratory tract dendritic cells preferentially stimulate $\mathrm{Th} 2$ responses and require obligatory cytokine signals for induction of Th1 immunity. F Exp Med 1998;188:2019-31.

5 Steinman RM. The dendritic cell system and its role in immunogenicity.

Annu Rev Immunol 1991;9:27 1-96.
6 Corrigan CJ, Kay AB. T-cells and eosinophils in the pathogenesis of asthma. Corrigan CJ, Kay AB. T-cells and
Immunol Today 1992;13:501-7.

Immunol Today 1992;13:501-7.
Poston RN, Chanez P, Lacoste JY, et al. Immunohistochemical characterisation of the cellular infiltration in asthmatic bronchi. Am Rev Respir Dis 1992;145:918-21.

8 Holt PG, Haining S, Nelson DJ, et al. Origin and steady-state turnover of class II MHC-bearing dendritic cells in the epithelium of the conducting airways. F Immunol 1994;153:256-61.

9 Nelson DJ, McMenamin C, McWilliam AS, et al. Development of the airway intraepithelial dendritic cell network in the rat from class II MHC (Ia) negative precursors: differential regulation of Ia expression at different levels of the respiratory tract. F Exp Med 1994;179:203-12.

10 Nelson DJ, Holt PG. Defective regional immunity in the respiratory tract of neonates is attributable to hyporesponsiveness of local dendritic cells to neonates is attributable to hyporesponsiveness of
activation signals. F Immunol 1995;155:3517-24.

11 Holt PG, Macaubas C, Stumbles PA, et al. The role of allergy in the development of asthma. Nature 1999;402:B12-17.

12 Tschernig T, Debertin AS, Paulsen F, et al. Dendritic cells in the mucosa of the human trachea are not regularly found in the first year of life. Thorax 2001;56:427-31.

13 Stoltenberg L, Thrane PS, Rognum TO. Development of immune response markers in the trachea in the fetal period and the first year of life. Pediatr Allergy Immunol 1993;4:13-9.

14 Martinez FD, Holt PG. The role of microbial burden in the aetiology of allergy and asthma. Lancet 1999;354:12-15.

Thorax 2001;56:420-422

\title{
Analysis of sputum in COPD
}

\author{
P Maestrelli, L Richeldi, M Moretti, L M Fabbri
}

A number of studies have suggested a pathogenetic role for airway inflammation in the induction of both chronic sputum production and chronic airflow obstruction in smokers. ${ }^{1}$ It is therefore important to characterise and quantify inflammatory changes in the assessment of subjects with chronic obstructive pulmonary disease (COPD). Assessment of inflammation may be achieved by different means including invasive methods such as bronchial biopsies, bronchoalveolar lavage (BAL) or examination of surgical specimens and non-invasive methods such as spontaneous or induced sputum.

The induction of sputum by inhalation of hypertonic saline is a safe, reliable, and relatively non-invasive method in COPD, provided the technique is performed in a standardised way and measures are used to prevent adverse reactions. $^{2-4}$ Induced sputum differs from spontaneous sputum by having a higher number of viable cells and less squamous cell contamination. ${ }^{3}$ There are no differences between spontaneous and induced samples from patients with COPD or asthma in the total and differential cell counts, but there is poor agreement in the fluid phase components. $^{56}$

Bronchial biopsies and BAL can be performed in COPD for investigative use according to the published recommendations. ${ }^{78}$ When the different methods of assessing airway inflammation are compared in the same subjects, a different 
profile of inflammatory cells is obtained depending on the compartment of the lung examined by each technique - that is, the lumen of the central airways using sputum analysis, ${ }^{9}$ the airway wall using bronchial biopsies, and the peripheral airways using BAL. ${ }^{10}$ By combining these techniques, integrated and comprehensive information on cell traffic and inflammatory processes in COPD at different levels of the airway can be obtained. Analysis of induced or spontaneous sputum has contributed to the identification of smokers susceptible to developing COPD, to the characterisation of the inflammatory process during exacerbations, and to the effects of intervention with anti-inflammatory drugs or by smoking cessation.

\section{Characterisation of susceptible smokers}

Cigarette smoking is the most important cause of COPD but only a few smokers will develop clinically overt disease. ${ }^{1}$ Cigarette smoke stimulates alveolar macrophages and possibly epithelial cells to release inflammatory mediators such as leukotriene (LT) $\mathrm{B}_{4}$, tumour necrosis factor (TNF) $\alpha$, and interleukin (IL) $-8^{11}{ }^{12}$ that may induce influx of neutrophils into the lung. ${ }^{13-15}$ The mechanisms for the increased susceptibility in some smokers and the identification early in life of high risk smokers remain unknown. A longitudinal study of smokers examined whether the airway inflammatory process is different in smokers susceptible to developing COPD from that in "resistant" smokers. The percentage of sputum neutrophils was greater in smokers with COPD than in asymptomatic smokers and correlated with the annual decline in forced expiratory volume in one second $\left(\mathrm{FEV}_{1}\right) \cdot{ }^{16}$ In addition, sputum neutrophils in COPD exhibited increased expression of adhesion molecule CD11b/CD18, the ICAM-1 ligand, and this expression was related to the degree of airway obstruction. ${ }^{17}$ A number of subsequent studies confirmed increased airway neutrophilia in patients with COPD compared with healthy smokers. ${ }^{18-20}$ It is likely that neutrophils accumulate in the airway lumen by recruitment from the circulation but, because of the rapid migration across the tissue, their numbers in the subepithelial layer of the airways at any time point are low. ${ }^{21}$ The mechanisms for the airway neutrophilia in COPD are not entirely clear, but imbalance between pro-inflammatory and anti-inflammatory cytokines has been suggested to play a role. Concentrations of IL-10 are reduced, while increased concentrations of IL- 8 and TNF $\alpha$ have been reported in the sputum of patients with COPD. ${ }^{11}{ }^{19}$ Macrophages and lymphocytes which exhibited activation markers in COPD (CD25, VLA-1, HLA), as well as epithelial cells, may be the source of the cytokines that, in turn, increase expression of adhesion molecules $(\mathrm{TNF} \alpha)$ and promote neutrophil chemotaxis (IL-8). Upregulation of E-selectin on vessels in the submucosa and increased expression of epithelial intercellular adhesion molecule (ICAM) 1 on basal epithelial cells in patients with COPD suggest a mechanism for recruitment of these cells from the circulation and for their migration to the airway lumen. ${ }^{22}$ Indeed, increased numbers of neutrophils were detected in the bronchial epithelium and the mucous glands of patients with COPD. ${ }^{23}$

Taken together, these data suggest that there is no clear qualitative difference-but rather a quantitative difference-between the inflammatory process in the airway lumen of patients with COPD and that of healthy smokers. This contrasts with asthma where eosinophils and eosinophil products represent the prominent inflammatory feature which is virtually absent in normal control subjects.

\section{Eosinophilic bronchitis}

A proportion of patients with COPD exhibited some degree of sputum eosinophilia. ${ }^{18202425}$ It is debatable whether the eosinophilia in COPD is related to concomitant features of asthma. Patients with COPD who responded to corticosteroid treatment or exhibited more reversibility of airway obstruction to salbutamol had significantly more eosinophils in their airways than those who did not. ${ }^{26}{ }^{27}$ In contrast, patients with exacerbations of chronic bronchitis who exhibited airway eosinophilia were indistinguishable by common diagnostic criteria and pathological findings from those without eosinophilia. ${ }^{25} \mathrm{It}$ has been suggested that the presence of eosinophils in the airways is related to the intensity of the inflammatory process in COPD, leading to non-specific recruitment of these cells $^{1824}$ and their activation. ${ }^{28}$ This is supported by the finding that the more severe impairment in $\mathrm{FEV}_{1}$ occurred in cases in which both sputum neutrophilia ${ }^{11}{ }^{16}{ }^{10}$ and sputum eosinophilia ${ }^{1620}$ were more intense, with a direct relationship between neutrophil and eosinophil numbers. ${ }^{20}$ In any case, the ability to detect eosinophilic bronchitis in patients with COPD may have clinical importance since this variant of COPD seems to respond to treatment with corticosteroids. ${ }^{29-31}$

\section{COPD exacerbations}

Patients with COPD are prone to exacerbations which are defined on clinical grounds by increased dyspnoea, cough, and sputum production that causes the subjects to seek medical attention. A proportion of patients with chronic bronchitis and mild airflow obstruction examined during exacerbations were found to have accumulation of neutrophils and eosinophils in sputum and their bronchial biopsy specimens exhibited increased numbers of mucosal eosinophils, similar in degree to that present in asthma. ${ }^{25}$ However, the influx of eosinophils in COPD was not associated with IL-5 expression, which suggests that a different mechanism induces eosinophilia in asthma and COPD. ${ }^{32} \mathrm{~A}$ recent study compared a large cohort of patients with severe COPD during an exacerbation with patients with stable COPD but failed to show any difference in sputum total and differential cell counts between the two groups. ${ }^{33}$ The only difference in the exacerbated group was a higher concentration of IL- 6 in the fluid phase of the sputum. In even more severe patients with an exacerbation of bacterial origin, Crooks et $a l^{34}$ found striking changes in the spontaneously induced sputum with increased levels of products from neutrophils (myeloperoxidase and elastase) and chemoattractants for neutrophils (IL-8 and $\mathrm{LTB}_{4}$ ). Moreover, the high proteinase inhibitor sputum to serum ratio suggested increased vascular permeability. The heterogeneity of the disease, the differences in baseline severity of patients, and the variable aetiology of exacerbations account for the discrepancies between the studies. Application to the analysis of induced sputum of molecular biology tools such as the polymerase chain reaction, which is much more sensitive than conventional tools, has been useful in assessing the aetiology of COPD exacerbations. In particular, the detection of rhinovirus nucleic acid in the induced sputum from a significant number of patients with COPD during clinical exacerbations, ${ }^{35}$ together with the expression of pro-inflammatory cytokines such as IL- $6,{ }^{36}$ suggests that COPD exacerbations may be at least partly due to an exaggerated inflammatory process primarily caused by a viral infection.

\section{Effect of interventions}

The question whether reducing risk factors - for example, smoking cessation and anti-inflammatory drugs-may reverse the inflammatory process in the airways of patients with COPD has been debated and has prompted a series of trials. However, direct assessment of airway inflammation has only been performed in a few studies. 
Although it is established that smoking cessation can stop the progression of COPD, there is no evidence that the airway inflammatory process is decreased in ex-smokers compared with current smokers. Sputum neutrophilia and the degree of integrin expression on sputum leucocytes is similar in ex-smokers and current smokers. ${ }^{16}{ }^{17}$ A significant increase in the percentage of sputum neutrophils and eosinophils, as well as in the concentrations of IL-8 and eosinophil cationic protein (ECP), has been shown in ex-smokers with COPD compared with ex-smokers without the disease. ${ }^{18}$ The persistence of granulocyte influx into the luminal compartment of the airways in ex-smokers is consistent with the persistence of the inflammatory process in the walls of the central airways seen in pathological studies. ${ }^{37} 38$

Treatment with oral and inhaled glucocorticosteroids for 2 weeks in a controlled study failed to modify the inflammatory indices in induced sputum of patients with COPD. ${ }^{39}$ A more prolonged study of treatment with $1.5 \mathrm{mg}$ inhaled fluticasone propionate for 8 weeks in patients with COPD led to a reduction in chemotactic activity and an increase in elastase inhibitory capacity of spontaneous sputum sol phase, suggesting that fluticasone may reduce neutrophil recruitment to the lung and favour antiproteinases within lung secretions. ${ }^{40}$ This mechanism could explain the reduction in sputum neutrophils observed in an uncontrolled study of patients with COPD treated with $1.5 \mathrm{mg}$ beclomethasone dipropionate for 8 weeks. ${ }^{41}$ The effect of steroids on COPD inflammation remains controversial except for their expected activity on eosinophils, when present. ${ }^{42}$ Further studies are required to determine the long term effects of drugs on lung secretions and to establish whether new treatments addressed to more specific targets will be effective.

Supported by the Italian Ministry of University and Research (MURST 40\%) and by the Universities of Padova, Ferrara and Modena.

Correspondence to: Dr P Maestrell

pieromaestrelli@unipd.it

Department of Environmental Medicine and Public Health,

P MAESTRELLI

University of Padova, 35128 Padova, Italy

L RICHELDI

M MORETTI

Department of Medicine, Oncology and Radiology,

L M FABBRI

University of Modena and Reggio Emilia, Italy

1 Global Initiative for Chronic Obstructive Lung Disease (GOLD). A collaborative project of the National Health, Lung, and Blood Institute, NIH and the World Health Organisation. 2001 (in press).

2 Rytila PH, Lindqvist AE, Laitinen LA. Safety of sputum induction in chronic obstructive pulmonary disease. Eur Respir f 2000;15:1116-9.

3 Bhowmik A, Seemungal TAR, Sapford RJ, et al. Comparison of spontaneous and induced sputum for investigation of airway inflammation in chronic obstructive pulmonary disease. Thorax 1998;53:953-6.

4 Falco F, Santamaria I, Guerzoni P, et al. Sputum induction is a safety technique in COPD patients. Eur Respir f 1998;12(Suppl 28):365s.

5 Pizzichini MMM, Popov TA, Efthimiadis AE, et al. Spontaneous and induced sputum to measure indices of airway inflammation in asthma. Am f Respir Crit Care Med 1996;154:866-9.

6 Moretti M, Falco F, Santamaria I, et al. Spontaneous and induced sputum to measure indices of airway inflammation in COPD. Eur Respir $f$ 1999;14(Suppl 30):24s

7 Workshop Summary and Guidelines. Investigative use of bronchoscopy, lavage, and bronchial biopsies in asthma and other airway diseases. $\mathcal{F}$ Allergy Clin Immunol 1991:88:808-14.

8 Djukanovic R, Dahl R, Jariour $\mathrm{N}$, et al. Safety of biopsies and bronchoalveolar lavage. Eur Respir f 1998;11(Suppl 26):39-41s.

9 Alexis NE, Hu SC, Zeman K, et al. Location of induced sputum derived cells and fluid phase components: identification using a radiolabeled aerosol bolus delivery technique. Am f Respir Crit Care Med 2000;161:A761.

10 Maestrelli P, Saetta M, Di Stefano A, et al. Comparison of leukocyte counts in sputum, bronchial biopsies, and bronchoalveolar lavage. Am F Respir Crit Care Med 1995;152:1926-31.
11 Keatings VM, Collins PD, Scott DM, et al. Differences in interleukin-8 and tumor necrosis factor- $\alpha$ in induced sputum from patients with chronic obstructive pulmonary disease or asthma. Am 7 Respir Crit Care Med 1996; 153:530-4.

12 Masubuchi T, Hoyama S, Sato E, et al. Smoke extract stimulates lung epithelial cells to release neutrophil and monocyte chemotactic activity. $\mathrm{Am}$ f Pathol 1998;153:1903-12.

13 Hunninghake GW, Crystal RG. Cigarette smoking and lung destruction. Accumulation of neutrophils in the lungs of cigarette smokers. Am Rev Respir Dis 1983;128:833-88.

14 Wright JL, Lawson LM, Pare PD, et al. Morphology of peripheral airways in current smokers and ex-smokers. Am Rev Respir Dis 1983;127:474-7.

15 Thompson AB, Daughton D, Robbins RA, et al. Intraluminal airway inflammation in chronic bronchitis: characterization and correlation with clinical parameters. Am Rev Respir Dis 1989;140:1527-37.

16 Stanescu D, Sanna A, Veriter C, et al. Airway obstruction, chronic expectoration, and rapid decline of $\mathrm{FEV}_{1}$ in smokers are associated with increased sputum neutrophils. Thorax 1996;51:267-71.

17 Maestrelli P, Calcagni PG, Saetta M, et al. Integrin upregulation on sputum neutrophils in smokers with chronic airway obstruction. Am f Respir Crit Care Med 1996;154:1296-300.

18 Rutgers SR, Postma DS, ten Hacken NH, et al. Ongoing airway inflammation in patients with COPD who do not currently smoke. Thorax 2000;55: $12-18$.

19 Takanashi S, Hasegawa Y, Kanehira Y, et al. Interleukin-10 level in sputum is reduced in bronchial asthma, COPD and in smokers. Eur Respir f 1999; 14:309-14.

20 Balzano G, Stefanelli F, Iorio C, et al. Eosinophilic inflammation in stable chronic obstructive pulmonary disease. Relationship with neutrophils and airway function. Am 7 Respir Crit Care Med 1999;160:1486-92.

21 Di Stefano A, Turato G, Maestrelli P, et al. Airflow limitation in chronic bronchitis is associated with T-lymphocyte and macrophage infiltration of the bronchial mucosa. Am f Respir Crit Care Med 1996;153:629-32.

22 Di Stefano A, Maestrelli P, Roggeri A, et al. Upregulation of adhesion molecules in the bronchial mucosa of subjects with chronic obstructive ecules in the bronchial mucosa of subjects with chro
bronchitis. Am f Respir Crit Care Med 1994;149:803-10.

23 Saetta M, Turato G, Facchini FM, et al. Inflammatory cells in the bronchial glands of smokers with chronic bronchitis. Am f Respir Crit Care Med 1997; 156:1633-9.

24 Gibson PG, Wooley KL, Carty K, et al. Induced sputum eosinophil cationic protein (ECP) measurement in asthma and chronic obstructive airway disease (COAD) Clin Exp Allergy 1998;28:1081-8.

25 Saetta M, Di Stefano A, Maestrelli P, et al. Airway eosinophilia in chronic bronchitis during exacerbations. Am f Respir Crit Care Med 1994;150: 1646-52.

26 Chanez P, Vignola AM, O'Shaugnessy, et al. Corticosteroid reversibility in COPD is related to features of asthma. Am $\mathcal{F}$ Respir Crit Care Med 1997;155:1529-34.

27 Papi A, Romagnoli M, Baraldo S, et al. Partial reversibility of airflow limitation and increased exhaled NO and sputum eosinophilia in chronic obstructive pulmonary disease. Am $\mathcal{f}$ Respir Crit Care Med 2000;162:17737 .

28 Keatings VM, Barnes PJ. Granulocyte activation markers in induced sputum: comparison between chronic obstructive pulmonary disease, sputum: comparison between chronic obstructive pulmonary disease,

29 Fujimoto K, Kubo, Yamamoto H, et al. Eosinophilic inflammation in the airway is related to glucocorticoid reversibility in patients with pulmonary emphysema. Chest 1999:115:697-702.

30 Pizzichini E, Pizzichini MM, Gibson P, et al. Sputum eosinophilia predicts benefit from prednisone in smokers with chronic obstructive bronchitis. Am $\mathcal{F}$ Respir Crit Care Med 1998;158:1511-7.

31 Brightling CE, Monteiro W, Ward R, et al. Sputum eosinophilia and shortterm response to prednisolone in chronic obstructive pulmonary disease: a randomised controlled trial. Lancet 2000;356:1480-5.

32 Saetta M, Di Stefano A, Maestrelli P, et al. Airway eosinophilia and expression of interleukin-5 protein in asthma and in exacerbations of chronic bronchitis. Clin Exp Allergy 1996;26:766-74.

33 Bhowmik A, Seemungal TAR, Sapsford RJ, et al. Relation of sputum inflammatory markers to symptoms and lung function changes in COPD exacerbations. Thorax 2000;55:114-20.

34 Crooks SW, Bayley DL, Hill SL, et al. Bronchial inflammation in acute bacterial exacerbations of chronic bronchitis: the role of leukotriene B4. Eur Respir f 2000;15:274-80.

35 Gern JE, Galagan DM, Jarjour NN, et al. Detection of rhinovirus RNA in lower airway cells during experimentally induced infection. Am f Respir Crit Care Med 1997; 155:1159-61.

36 Seemungal TAR, Harper-Owen R, Bhowmik A, et al. Detection of rhinovirus in induced sputum at exacerbation of chronic pulmonary disease. Eur Respir f 2000;16:677-83.

37 Mullen JBM, Wright JL, Wiggs BR, et al. Structure of central airways in current smokers and ex-smokers with or without hypersecretion: relationship to lung function. Thorax $1987 ; 42: 843-8$.

38 Turato G, Di Stefano A, Maestrelli P, et al. Effect of smoking cessation on airway inflammation

39 Keatings VM, Jatakanon A, Worsdell YM, et al. Effects of inhaled and oral glucocorticoids on inflammatory indices in asthma and COPD. Am $\mathcal{F}$ Respir Crit Care Med 1997;155:542-8.

40 Llewellyn-Jones CG, Harris TA, Stockley RA. Effect of fluticasone propionate on sputum of patients with chronic bronchitis and emphysema. Am $\mathcal{F}$ ate on sputum of patients with chronic
Respir Crit Care Med 1996;153:616-21.

41 Confalonieri M, Mainardi E, Della Porta R, et al. Inhaled corticosteroids reduce neutrophilic bronchial inflammation in patients with chronic obstructive pulmonary disease. Thorax 1998;53:583-5.

42 Hargreave FE, Leigh R. Induced sputum, eosinophilic bronchitis, and chronic obstructive pulmonary disease. Am $\mathcal{F}$ Respir Crit Care Med 1999;160:S53-7 


\title{
AIDS and the lung in a changing world
}

\author{
C Mayaud, J Cadranel
}

At the beginning of the AIDS epidemic it was clear that the lung of HIV infected patients was the major target for many infections and tumours. ${ }^{12}$ However, during the first decade of the disease it was shown that the occurrence of several infections might be prevented by the use of prophylaxis, which has a direct but temporary effect, ${ }^{3}$ and more recently the use of highly active antiretroviral therapy (HAART) has been shown to have an indirect (immune restoration) but long lasting effect. ${ }^{4-7}$ Thus, in a changing world, today we have three different situations.

First situation: HIV infected patients without access to prophylaxis for pulmonary infections and antiretroviral treatment

Unfortunately, this situation applies to the great majority of HIV infected patients in developing countries and, in developed countries, to those without knowledge of their HIV seropositivity or without appropriate follow up.

In this situation the natural history of HIV associated lung disorders is obviously the same as it was at the beginning of the AIDS epidemic. The range of pathogens possibly responsible for respiratory diseases is very wide with a high frequency of acute bronchitis, bacterial pneumonia, Pneumocystis carinii pneumonia (PCP), and tuberculosis. ${ }^{18}$ Similarly, the variety of non-infectious causes of respiratory disease is also very broad $^{2}$ with Kaposi's sarcoma, lymphoid interstitial pneumonitis and, to a lesser degree, lymphoma, emphysema, ${ }^{9}$ and primary pulmonary hypertension ${ }^{10}$. In contrast, a link between HIV infection and lung cancer, ${ }^{11}$ pulmonary embolism, or bronchial hyperreactivity still remains questionable. New clinical entities such as cytomegalovirus induced alveolar haemorrhage, ${ }^{12}$ primary pulmonary lymphoma, ${ }^{13}$ and rapidly worsening airway obstruction associated with bronchiectasis ${ }^{14}$ have recently been reported in HIV infected patients.

The incidence and prevalence of each of these respiratory disorders are strongly related to two factors. The first is the level of immunosuppression-the relative risks for bacterial pneumonia, tuberculosis, PCP, or fungal infections such as cryptococcosis and aspergillosis are clearly related to the gradual decrease in CD4 lymphocyte count. The second factor is the country in which patients live. In Europe and the USA PCP was the most frequent severe lung disease before PCP prophylaxis became available, ${ }^{15}$ while in Africa bacterial pneumonia and tuberculosis were the main causes of severe lung disease. ${ }^{16-19}$ However, even within the continent of Africa, recent series have shown that the relative frequencies of lung diseases may differ from one country to another. This is particularly true in HIV infected patients with acute pneumonia unresponsive to standard antibiotics and sputum smear negative for acid fast bacilli. Fibreoptic bronchoscopy systematically performed in such patients has shown a high frequency of non-specific interstitial pneumonia (38\% of cases), tuberculosis (23\%), and cryptococcosis (13\%) in Rwanda ${ }^{20}$ and, in contrast, a high frequency of tuberculosis (39\%), PCP (33\%), and Kaposi's sarcoma (9\%) in Zimbabwe. ${ }^{21}$ Similarly, a recent study in Phnom-Penh using fibreoptic bronchoscopy with bronchoalveolar lavage (BAL) in HIV infected patients with unexplained pneumonia frequently found Mycobacterium tuberculosis (33\% of cases) but also $P$ carinii (25\%) and atypical mycobacteria (17\%) (S Chan, personal communication, 1998).

Clearly, local studies should be performed in each developing country with a significant number of HIV infected patients to determine the relative frequencies of respiratory diseases. This knowledge will be essential for selecting the most appropriate management algorithm for pneumonia and choosing the most effective prophylaxis.

Second situation: HIV infected patients with access to prophylaxis for pulmonary infections but not to antiretroviral treatment

During the first decade of the AIDS epidemic this situation applied to most of the patients in developed countries and currently it applies to a large number of HIV infected patients in developing countries.

In patients who are not receiving antiretroviral treatment, particularly HAART, the prophylaxis of pulmonary infections remains a major goal because of the high incidence and short term mortality resulting from these infections and because they increase the rate of HIV replication and accelerate the course of the disease. ${ }^{22}{ }^{23} \mathrm{In}$ practice, prophylaxis should aim mainly at the prevention of PCP, tuberculosis, and bacterial pneumonia because these three infections together account for at least $80 \%$ of severe lung diseases in all countries. ${ }^{81521}$

The USPHS/IDSA guidelines for PCP prophylaxis are clear. Primary prophylaxis is indicated in all cases, including pregnant women, with a CD4 titre of less than $200 / \mathrm{mm}^{3}$ or a history of oropharyngeal candidiasis. Secondary prophylaxis is indicated in all patients with a prior episode of PCP. Trimethoprim-sulphamethoxazole (TMP-SMZ) is the drug of choice $^{24}$ and its effectiveness in the prevention of PCP has been clearly shown in several prospective randomised trials. ${ }^{25}{ }^{26}$ However, one practical problem and one theoretical question still persist about this prophylaxis.

The practical problem is the best strategy to use in patients with TMP-SMZ intolerance. ${ }^{25} 26$ Three steps might be proposed according to the severity of the side effects: (1) to continue TMP-SMZ with a decrease in dose or frequency ${ }^{25}$; (2) to withdraw TMP-SMZ and then to reintroduce it in progressively increasing doses (desensitisation) according to published regimens ${ }^{24} ;(3)$ to switch to another prophylactic drug such as dapsone $e^{25}$ or atovaquone. ${ }^{27}$

The theoretical question deals with the possible consequences of the long term use of TMP-SMZ and, more particularly, the risk of emergence of TMP-SMZ resistant $P$ carinii. In a retrospective study Helweg-Larsen et $a l^{28}$ have shown that $P$ carinii presents mutations on the impact side of TMP-SMZ in $20 \%$ of episodes of PCP. The mutations were significantly more common in patients previously exposed to sulphonamides and, in a multivariate analysis, the presence of these mutations was found to be the most important predictor of death related to PCP. These data suggest that resistance to sulphonamides may result from PCP dihydropteroate synthase gene mutations $^{29}{ }^{30}$ and raise the PCP mortality rate. If this is the case, the theoretical question could become a practical problem.

In the USPHS/IDSA guidelines primary prophylaxis of tuberculosis is indicated in two groups of HIV infected 
patients: those in close contact with persons with infectious tuberculosis and those with a positive purified protein derivative (PPD) test. In both groups primary prophylaxis should only be started after active tuberculosis has been excluded by clinical and radiological evaluation. Treatment with isoniazid for 9 months or rifampin (or rifabutin) plus pyrazinamide for 2 months is equally effective. Secondary prophylaxis is not recommended. ${ }^{24}$ The effectiveness of isoniazid given for 6 or 12 months as primary prophylaxis has recently been confirmed by a meta-analysis of seven randomised trials, four of which were performed in Africa, ${ }^{31}$ which confirmed that isoniazid reduced the risk of tuberculosis in patients with a positive PPD test. However, isoniazid did not reduce the mortality (resulting from HIV infection) in any group of patients.

If tuberculosis prophylaxis is theoretically justified in all patients with a positive PPD test, ${ }^{32}$ some practical questions remain to be answered:

- What is the feasibility of the widespread diffusion of such prophylaxis within tuberculosis and AIDS programme conditions in developing countries? ?3 $^{33}$

- What is the risk of an increase in tuberculosis resistance to isoniazid and/or rifampin, ${ }^{34}$ particularly if prophylaxis is given to patients with active tuberculosis?

- What is the optimal duration of prophylaxis since no prophylaxis is able to eradicate the whole population of $M$ tuberculosis or to protect against reinfection? ${ }^{35}$

With regard to the high level of tuberculosis "recurrences" in some developing countries, Fitzgerald et al have recently performed a randomised trial of secondary prophylaxis (isoniazid versus placebo) in HIV infected patients after complete cure of tuberculosis and found that isoniazid decreased the risk of recurrence, particularly in HIV infected patients with a history of symptomatic HIV disease before the initial diagnosis of tuberculosis. ${ }^{36}$ As in studies of primary prophylaxis, isoniazid alone did not prolong survival, ${ }^{36}$ but mortality was reduced when isoniazid was combined with another anti-infectious agent such as sulphadoxine-pyrimethamine. ${ }^{37}$

The USPHS/IDSA guidelines for the prophylaxis of bacterial pneumonia mainly concern pneumococcal disease because of its high frequency and severity. Pneumococcal vaccine is indicated in all patients with a moderate level of immunosuppression and should be given as soon as possible after the diagnosis of HIV infection. ${ }^{24}$ These recommendations are based on the result of case-control or observational cohort studies. In a recent retrospective case-control study by Guerrero et al pneumococcal vaccine reduced the risk of pneumonia by nearly $70 \% .^{38}$ In the observational cohort study by Schuchat et $a \beta^{39}$ a significant reduction in the incidence of invasive as well as non-invasive pneumococcal disease was observed following pneumococcal vaccination, but only in patients with a CD4 cell count of more than $200 / \mathrm{mm}^{3}$. Finally, in a case-control study Breiman $e t a l^{40}$ found that the pneumococcal vaccine prevented invasive pneumococcal disease in $50 \%$ of subjects, after adjustment for CD4 cell count, but its effectiveness had not been observed in the subgroup of HIV infected patients of African origin. Because the incidence and recurrence rates of invasive pneumococcal disease are high in Africa, ${ }^{41}$ French et al $l^{42}$ evaluated the effectiveness of pneumococcal vaccine in a prospective randomised trial in a cohort of HIV infected Ugandan adults and were surprised to find that the vaccine was ineffective in the prevention of invasive as well as non-invasive pneumococcal diseases including those due to serotypes included in the vaccine. Moreover, the vaccine appeared to increase the risk of developing pneumonia, whatever the cause. French et al suggest that this harmful effect of pneumococcal polysaccharides might be due to the destruction of polysaccharide responsive B cell clones. ${ }^{42} 43$

Since the effectiveness and safety of pneumococcal vaccine are questionable, particularly in central Africa, it is logical to consider alternative strategies for protection, mainly chemoprophylaxis. ${ }^{43}$ In some prospective or casecontrol studies of PCP or Mycobacterium avium intracellulare (MAC) prophylaxis the use of TMP-SMZ ${ }^{44} 45$ or macrolides ${ }^{46}$ was associated with a low incidence of bacterial infections. ${ }^{24}$ Similarly, in a retrospective cohort study by Buskin et $a l^{47}$ TMP-SMZ lowered the risk of major infections and deaths not attributable to PCP. This beneficial effect has recently been evaluated in two prospective randomised trials in Abidjan (Côte d'Ivoire). ${ }^{48}{ }^{49}$ Anglaret et $a l^{48}$ administered TMP-SMZ to HIV infected patients in clinical stage 2 or 3 of the WHO classification and found a significant decrease in hospital admissions-mainly those due to bacterial pneumonia, malaria, isosporiasis, and acute unexplained fever-at 12 months. Wiktor et $a l^{49}$ administered TMP-SMZ to HIV infected patients with positive tuberculosis tests and found a significant decrease in hospital admissions, mainly those due to septicaemia or enteritis. Moreover, as in the study by Buskin et al, ${ }^{47}$ there was a significant decrease in mortality, particularly among patients with a low CD4 cell count. ${ }^{49}$

Considering these results and the limits of pneumococcal vaccination, ${ }^{42}$ it may be attractive to recommend the use of TMP-SMZ as systematic prophylaxis in all developing countries with a significant number of HIV infected patients. However, before doing so there are four questions to consider:

- Which patients are likely to benefit from TMP-SMZ: those treated for tuberculosis ${ }^{49}$ and/or those with any HIV related symptoms ${ }^{48}$ and/or those with a CD4 cell count of less than $500 / \mathrm{mm}^{3}$ ?

- What is the effectiveness of TMP-SMZ prophylaxis in countries where the percentage of TMP-SMZ resistant bacteria is high ${ }^{48}$

- What is the effectiveness of TMP-SMZ prophylaxis in countries without malaria? ${ }^{48}$

- What is the long term risk of increasing the resistance of usual bacteria to TMP-SMZ ? $^{24}$ For example, the frequency of TMP-SMZ resistant bacteria has recently increased in HIV units in San Francisco and this increase coincided with the increase in prophylactic use of TMP-SMZ in HIV infected patients. The frequency of TMP-SMZ resistant bacteria has also increased in non-HIV units and multidrug resistance has been reported. ${ }^{50}$

In many developing countries without access to antiretroviral treatment, prophylaxis could significantly reduce morbidity and mortality in HIV infected patients. Effective regimens exist to prevent PCP, tuberculosis, and bacterial pneumonia. However, each country must determine the most appropriate prophylaxis strategy, taking into account the local spectrum of infections and the local prevalence of resistant pathogens. Whatever the prophylactic programme chosen, it is very important to evaluate periodically the susceptibility of the pathogens to the drugs used. ${ }^{24}$

Third situation: HIV infected patients with access to prophylaxis for pulmonary infections and to HAART The first and major beneficial effect of HAART is a dramatic reduction in the occurrence of opportunistic infections and, to a lesser degree, of Kaposi's sarcoma. $^{675152}$ For example, in the French epidemiological database with follow up data on more than $34000 \mathrm{HIV}$ infected patients in 1998, the incidence of PCP per 10000 people years decreased from 174 in 1995 to 47 in $1998 .^{53}$ During the same period a similar decrease in the incidence 
of cytomegalovirus disease, MAC disease, toxoplasmosis, and Kaposi's sarcoma was observed. Interestingly, the remaining opportunistic infections occurred at a high level of immunosuppression whatever the period and, in 1998, they were almost exclusively observed in patients who had not received HAART or in whom it had been ineffective. ${ }^{53}$ It is therefore reasonable to try to withdraw the prophylactic treatment of opportunistic infections from patients successfully treated with HAART. Prospective and retrospective studies have shown that the risk associated with the arrest of primary or secondary prophylaxis against PCP appears to be quite low in patients receiving HAART whose CD 4 cell counts have risen above $200 / \mathrm{mm}^{3}$ for 3 or 6 months. ${ }^{51-56}$ Similar results have been obtained with other opportunistic infections. Specific prophylactic regimens can therefore be safely discontinued in patients in whom CD4 cell counts have increased above the thresholds for initiating prophylaxis. ${ }^{24} 51$ Similarly, in cases of delayed HAART failure it seems reasonable to use the same criteria for restarting prophylaxis as for initiating it. ${ }^{51}$

The second beneficial effect of HAART is a reduction in the occurrence of tuberculosis and bacterial pneumonia. However, this reduction is limited, particularly for bacterial pneumonia. In the French epidemiological database the incidence of tuberculosis per 10000 people years decreased from 84 in 1995 to 36 in 1998 and the incidence of bacterial pneumonia from 279 in 1995 to 192 in $1998 .^{53}$ Unlike the other opportunistic infections, bacterial pneumonia and tuberculosis occurred with a lesser degree of immunosuppression in 1998 than in 1995. At this level of immunosuppression Streptococcus pneumoniae and Haemophilus influenzae were the causal organisms, but not Pseudomonas. Clearly, the risk of tuberculosis and/or bacterial pneumonia decreases but still persists in patients successfully treated with HAART. If we remember that acute pneumonia is a major cause of death in HIV infected patients before AIDS stage, ${ }^{52}$ the preventive treatment of both infections might be a major goal in this situation. Thus, pneumococcal vaccination or isoniazid prophylaxis might be given to patients on HAART with, respectively, a CD 4 cell count reaching $200 / \mathrm{mm}^{3}$ or with conversion from a negative to a positive PPD test.

Unfortunately, there are some harmful effects of HAART, either directly or indirectly. The first of these is the paradoxical worsening of opportunistic pneumonia after initiation of HAART. ${ }^{52}$ In a prospective study Narita et $a \bar{t}^{8}$ examined the incidence of paradoxical responses in patients treated for pulmonary tuberculosis and found a higher incidence $(36 \%)$ in HIV infected patients receiving antituberculosis treatment and HAART than in HIV negative patients receiving antituberculosis therapy $(2 \%)$ or in HIV positive patients receiving antituberculous treatment but not HAART $(7 \%)$. The paradoxical responses were either worsening of initial localisations of tuberculosis or the occurrence of apparently new localisations of tuberculosis in spite of adequate antituberculous treatment. It is noteworthy that these paradoxical responses occurred a long time after the initiation of antituberculous therapy but a short time after the initiation of HAART. In all cases HAART was rapidly successful — as shown by a marked fall in the HIV viral load and conversion from a negative to a positive PPD test - at the time of the paradoxical response. More recently we have described three cases of acute respiratory failure following early introduction of HAART in patients treated for PCP. ${ }^{59}$ The three patients had severe PCP that initially improved with anti-PCP and adjunctive steroid treatment but 7-17 days after introduction of HAART they developed a second episode of severe acute respiratory failure with fever and patchy alveolar opacities.
Bronchoalveolar lavage and transbronchial biopsy specimens showed severe non-specific pulmonary inflammatory foci surrounding a few persistent $P$ carinii cysts. All three patients recovered after stopping HAART and/or reintroducing steroids. These paradoxical responses probably result from the first phase of immunity restoration ${ }^{60}{ }^{61}$ with rapid pulmonary recruitment of fully competent immune and inflammatory cells responding to a few persistent $M$ tuberculosis or $P$ carinii. Similar immune and inflammatory responses probably contribute to other clinical manifestations of immunologically mediated diseases observed after initiation of HAART. ${ }^{52}$ Similarly, Morris et $a l^{62}$ recently reported the case of an HIV infected woman who developed subacute hypersensitivity pneumonitis in response to bird exposure only after a rapid improvement in her CD4 $\mathrm{T}$ lymphocyte count secondary to starting HAART.

A second harmful effect of HAART is the emergence of sarcoid like pulmonary disorders. We have recently reported two HIV infected patients with diffuse opacities, thoracic adenopathy, CD4 lymphocytic alveolitis, parotid or salivary gland enlargement, increased serum levels of angiotensin converting enzyme, non-caseating granuloma, and a negative PPD test. These radiological and biological data were noted in patients with undetectable levels of HIV and a CD4 cell count of more than $200 / \mathrm{mm}^{3}$ as a result of long term HAART in one case and the association of HAART and interleukin (IL)-2 in the other. Antituberculous treatment was unsuccessful. In one case improvement was obtained when IL-2 was withdrawn. ${ }^{63}$ Since this first report we have collected six more cases (unpublished). The development of this sarcoid-like process may result from the second phase of immunity restoration which mainly involves the naive and IL-2 receptor positive T cells. ${ }^{6061}$

Another group of harmful effects of HAART are antiretroviral drug induced respiratory disorders. So far, lactic acidosis with tachypnoea or exercise induced dyspnoea is the most striking side effect reported with these drugs. ${ }^{63}$ However, recent communications have reported hypersensitivity reactions to abacavir. ${ }^{64}{ }^{65}$ Respiratory physicians should be particularly aware of these reactions for two principal reasons: (1) a respiratory symptom such as tachypnoea, cough, or pharyngitis associated with fever or rash is present in nearly $20 \%$ of hypersensitivity cases; and (2) in cases of rechallenge respiratory symptoms reappear within hours if they were present on the initial reaction. These symptoms are more severe and an adult respiratory distress syndrome (ARDS) associated with hypotension and tachycardia is present in $6 \%$ of cases. ${ }^{64}$ Moreover, ARDS may lead to death, as reported by Escaut et al. ${ }^{65}$

Finally, the interactions between antiretroviral drugs and anti-infectious drugs such as antituberculous agents are indirectly harmful. Rifamycin containing regimens are the most effective in curing tuberculosis in HIV infected patients but rifampin cannot be given with a protease inhibitor or a non-nucleoside inhibitor of reverse transcriptase because of their metabolic interactions. ${ }^{23}{ }^{66}{ }^{67} \mathrm{Cli}-$ nicians must therefore choose between three options: (1) standard antituberculous therapy without antiretroviral treatment; (2) standard antituberculous therapy with nucleoside inhibitors of reverse transcriptase; or (3) standard antituberculous therapy in which rifabutin at half the dose is substituted for rifampin. ${ }^{68}$

Whatever the harmful effects of HAART, they are considerably less than their beneficial effects. However, one practical problem still remains-namely, the optimal time for introduction of HAART in HIV infected patients with an opportunistic infection. Immediate introduction may avoid the increase in HIV replication and accelerate the cure of infections responding poorly to anti-infectious 
agents but delayed introduction may avoid a paradoxical response, a cumulative number of side effects, and some drug interactions. This question remains to be answered.

The authors thank Patricia Yvernault and Lydie Fromont for their technical assistance.

\section{MAYAUD} J CADRANEL

Service de Pneumologie et de Réanimation Respiratoire,

Hôpital Tenon, 4 rue de la Chine, 75020 Paris, France

charles.mayaud@tnn.ap-hop-paris.fr

1 Murray JF, Mills J. Pulmonary infectious complications of HIV infection. Am Rev Respir Dis 1990;141:1356-72, 1582-98.

2 White D, Matthay R. Non infectious pulmonary complications of infection with the HIV. Am Rev Respir Dis 1989;140:1763-87.

3 Hoover D, Saar A, Bacellar H et al. Clinical manifestations of AIDS in the era of pneumocystis prophylaxis. Multicenter AIDS cohort study. $\mathrm{N} \mathrm{Engl} \mathcal{F}$ Med 1993;329:1922-6.

4 Rodt R, Kamps B, Gute $\mathrm{P}$ et al. Changing incidence of AIDS-defining illnesses in the era of antiretroviral combination therapy. AIDS 1997;11:1731-8.

5 Sepkowitz K. Effect of HAART on natural history of AIDS-related opportunistic disorders, Lancet 1998;351:228-30.

6 Palella F, Delaney K, Moorman A et al. Declining morbidity and mortality among patients with advanced human immunodeficiency virus infection. $N$ Engl f Med 1998;338:853-60.

7 Mocroft A, Katlama C, Johnson A et al. AIDS across Europe, 1994-98 : the EuroSIDA study. Lancet 2000;356:291-6.

8 Wallace J, Hansen N, Lavange L et al. Respiratory disease trends in the pulmonary complications of HIV infection study cohort. Am $\mathcal{F}$ Respir Crit Care Med 1997;155:72-80.

9 Diaz P, King M, Pacht E et al. Increased susceptibility to pulmonary emphysema among HIV-seropositive smokers. Ann Intern Med 2000;132:369-72.

10 Opravil M, Pechere M, Speich R, et al. HIV-associated primary pulmonary hypertension. Am f Respir Crit Care Med 1997;155:990-5.

11 Tirelli U, Spina M, Sandri S, et al. Lung carcinoma in 36 patients with human immunodeficiency virus infection. Cancer 2000;88:563-9.

12 Herry I, Cadranel J, Antoine M, et al. Cytomegalovirus-induced alveolar hemorrhage in patients with AIDS: a new clinical entity? Clin Infect Dis 1996;22:616-20.

13 Bazot M, Cadranel J, Benayoun S, et al. Primary pulmonary AIDS-related lymphoma. Chest 1999;119:1282-6.

14 Bard M, Couderc L, Saimot A, et al. Accelerated obstructive pulmonary disease in HIV-infected patients with bronchiectasis. Eur Respir F 1998;11:771-5

15 Murray J, Felton C, Garay S, et al. Pulmonary complications of the AIDS. $N$ Engl f Med 1984;310:1682-8.

16 McLeod D, Neill P, Robertson V, et al. Pulmonary diseases in patients infected with the HIV in Zimbabwe, Central Africa. Trans $R$ Soc Trop Med Hyg 1989;83:694-7.

17 Lucas S, Hounnou A, Peacock C, et al. The mortality and pathology of HIV infection in a west African city. AIDS 1993;7:1569-79.

18 Scott J, Hall J, Muyodi C, et al. Aetiology, outcome and risk factors for mortality among adults with acute pneumonia in Kenya. Lancet 2000;355: $1225-9$

19 Kamanfu G, Mlika-Cabanne N, Girard P, et al. Pulmonary complications of human immunodeficiency virus infection in Bujumbura, Burundi. Am Rev Respir Dis 1993;147:658-63.

20 Batungwanayo J, Taelman H, Lucas S, et al. Pulmonary disease associated with the human immunodeficiency virus in Kigali, Rwanda. Am $\mathcal{F}$ Respir with the human immunodeficien
Crit Care Med 1994;149:1591-6.

21 Malin S, Gwanzura L, Klein S, et al. Pneumocystis carinii pneumonia in Zimbabwe. Lancet 1995;346:1258-61.

22 Chaisson R, Gallant J, Keruly J, et al. Impact of opportunistic disease on survival in HIV-infected patients. AIDS 1998;12:29-33.

23 Mayaud C, Cadranel J. Tuberculosis in AIDS: past or new problems? Tho$\operatorname{rax} 1999 ; 54: 567-71$

24 USPHS/IDSA Prevention of Opportunistic Infections Working Group. 1999 USPHS/IDSA guidelines for the prevention of opportunistic infections in persons infected with human immunodeficiency virus. Ann Intern Med 1999;131:873-908.

25 Bozzette S, Finkelstein D, Spector S, et al. A randomized trial of three antipneumocystis agents in patients with advanced human immunodeficiency virus infection. $N$ Engl $\mathcal{F}$ Med 1995;332:693-9.

26 Hardy W, Feinberg J, Finkelstein D, et al. A controlled trial of trimethroprim-sulfamethoxazole or aerosolized pentamidine for secondary prophylaxis of Pneumocystis carinii pneumonia in patients with the acquired prophylaxis of Pneumocystis carinu pneumonia in patients with the

27 El-Sadr W, Murphy R, McCabe Yurik T, et al. Atovaquone compared with dapsone for the prevention of Pneumocystis carinii pneumonia in patients with HIV infection who cannot tolerate trimethoprim, sulfamides or both. with HIV infection who cannot to

28 Helweg-Larsen J, Benfield T, Eugen-Olsen J, et al. Effects of mutations in Pneumocystis carinii dihydropteorate synthase gene on outcome of AIDS-associated P carinii pneumonia. Lancet 1999;354:1347-51.

29 Kazanjian P, Locke A, Hossler P, et al. Pneumocystis carinii mutations associated with sulfa and sulfone prophylaxis failures in AIDS patients. AIDS 1998;12:873-8

$30 \mathrm{Ma} \mathrm{L}$, Borio L, Masur $\mathrm{H}$, et al. P carinii dihydropteorate synthase but not dihydrofolate reductase gene mutations correlate with prior trimethoprimsulfamethoxazole or dapsone use. F Infect Dis 1999;180:1969-78.

31 Bucher H, Griffith L, Guyatt G, et al. Isoniazid prophylaxis for tuberculosis in HIV-infection: a meta-analysis of randomized controlled trials. AIDS 1999;13:501-7.

32 Rose DN. Short-course prophylaxis against tuberculosis in HIV-infected persons. A decision and cost effectiveness analysis. Ann Intern Med 1998;129:779-86.

33 Aisu T, Raviglione M, van Praag E, et al. Preventive chemotherapy for HIVassociated tuberculosis in Uganda: an operational assessment at a voluntary counselling and testing center. AIDS 1995;9:267-73.

34 Ridzon R, Whitney C, McKenna M, et al. Risk factors for rifampin monoresistant tuberculosis. Am F Respir Crit Care Med 1998;157:1881-4.
35 Halsey N, Coberly J, Desormeaux J, et al. Randomized trial of isoniazid versus rifampin and pyrazinamide for prevention of tuberculosis in HIV-infection. Lancet 1998;351:786-92.

36 Fitzgerald D, Desvarieux M, Severe P, et al. Effect of post-treatment isoniazid on prevention of recurrent tuberculosis in HIV-1 infected individuals: a randomized trial. Lancet 2000;356:1470-4.

37 Haller L, Rossouhounto R, Coulibaly I, et al. Isoniazid plus sulphadoxinepyrimethamine can reduce morbidity of HIV-positive patients treated for tuberculosis in Africa: a controlled clinical trial. Chemotherapy 1999;45: $452-65$.

38 Guerrero M, Kruger S, Saitoh A, et al. Pneumonia in HIV-infected patients: a case-control survey of factors involved in risk and prevention. AIDS 1999;13:1971-5.

39 Schuchat A, Breiman R, Dworkin M, et al. Observational studies of pneumococcal polysaccharide vaccine effectiveness among HIV-infected adults, USA, 1990-1998. Second International Symposium on Pneumococci and Pneumococcal Diseases, Sun City, 2000.

40 Breiman R, Keller D, Phelan M, et al. Evaluation of effectiveness of the 23-valent pneumococcal capsular polysaccharide vaccine for HIV-infected patients. Arch Intern Med 2000;160:2633-8.

41 Gilks C, Ojoo S, Ojoo J, et al. Invasive pneumococcal disease in a cohort of predominantly HIV-1 infected female sex-workers in Nairobi, Kenya. Lancet 1996;347:718-23.

42 French N, Nakiyingi J, Carpenter L, et al. 23-valent pneumococcal polysaccharide vaccine in HIV-1 Ugandan adults: double-blind, randomized and placebo controlled trial. Lancet 2000;355:2106-11.

43 French N. Mechanisms of failure of pneumococcal polysaccharide vaccine in HIV-infection and alternate approaches to prophylaxis. Second International Symposium on Pneumococci and Pneumococcal Diseases, Sun City, 2000

44 Hardy W, Feinberg J, Finkelstein D, et al. A controlled trial of trimethoprimsulfamethoxazole or aerosolized pentamidine for secondary prophylaxis of Pneumocystis carinii pneumonia in patients with the acquired immunodeficiency syndrome. N Engl f Med 1922;327:1482-8.

45 Edge M, Rimland D. Community acquired bacteremia in HIV-positive patients: protective benefit of cotrimoxazole. AIDS 1996;10:1635-9.

46 Navin T, Rimland D, Lennox J, et al. Risk factor for community-acquired pneumonia among persons infected with human immunodeficiency virus. f Infect Dis 2000;181:158-64.

47 Buskin S, Newcomer L, Koutsky L, et al. Effect of trimethoprimsulfamethoxazole as Pneumocystis carinii pneumonia prophylaxis on bacte-
rial illness, Pneumocystis carinii pneumonia and death in persons with rial illness, Pneumocystis carinii pneumonia and death in persons
AIDS. F Acquir Immune Defic Syndr Hum Retrovirol 1999;20:201-6.

48 Anglaret X, Chene G, Attia A, et al. Early chemoprophylaxis with trimethoprim-sulphamethoxazole for HIV-1 infected adults in Abidjan, Côte d'Ivoire: a randomized trial. Lancet 1999;353:1463-8.

49 Wiktor S, Sassan-Morokro M, Grant A, et al. Efficacy of trimethoprimsulphamethoxazole prophylaxis to decrease morbidity and mortality in HIV-1-infected patients with tuberculosis in Abidjan, Côte d'Ivoire: a randomized controlled trial. Lancet 1999;353:1469-75.

50 Martin J, Rose D, Hadley W, et al. Emergence of trimethoprim-sulfamethoxazole resistance in the AIDS era. F Infect Dis 1999;180:1809-18.

51 Kovacs J, Masur H. Prophylaxis against opportunistic infections in patients with human immunodeficiency virus infection. N Engl f Med 2000;342: $1416-29$.

52 Ledergerber B, Egger M, Erard V, et al. AIDS-related opportunistic illnesses occurring after initiation of potent antiretroviral therapy. $\mathcal{F} A M A 1999 ; 282$ : 2220-6.

53 Centre Coopérateur de Données Epidémiologiques sur l'Immunodéficience Humaine (B3E-INSERM SC4). Retour d'informations clinicoépidémiologiques. No 7, January 2000.

54 Furrer H, Egger M, Opravil M, et al. Discontinuation of primary prophylaxis against Pneumocystis carinii pneumonia in HIV-1-infected adults treated with combination antiretroviral therapy. N Engl f Med 1999;340:1301-6.

55 Weverling G, Mocroft A, Ledergerber B, et al. Discontinuation of Pneumocystis carinii pneumonia prophylaxis after start of highly active
antiretroviral therapy in HIV-1 infection. Lancet 1999;353:1293-8.

56 Soriano V, Dona C, Rodriguez-Rosado R, et al. Discontinuation of secondary prophylaxis for opportunistic infections in HIV-infected patients receiving highly active antiretroviral therapy. AIDS 2000;14:383-6.

57 Laurichesse H, Mortimer J, Evans B, et al. Pre-AIDS mortality in HIV-infected individuals in England, Wales and Northern Ireland 1982-1996. AIDS 1998:12:651-8.

58 Narita M, Ashkin D, Hollender E, et al. Paradoxical worsening of tuberculosis following antiretroviral therapy in patients with AIDS. Am f Respir Crit Care Med 1998;158:157-61.

59 Wislez M, Bergot E, Antoine $M$, et al. Acute respiratory failure following HAART introduction in patients treated for Pneumocystis carinii pneumonia. Am f Respir Crit Care Med 2001 (in press).

60 Autran B, Carcelain G, Li T, et al. Positive effects of combined antiretroviral therapy on CD4+ $\mathrm{T}$ cell homeostasis and function in advanced HIV disease. Science 1997;277:112-6.

61 Pakker N, Notermans D, de Boer R, et al. Biphasic kinetics of peripheral blood $\mathrm{T}$ cells after triple combination therapy in HIV-1 infection: a composite of redistribution and proliferation. Nature Med 1998;4:208-14.

62 Morris A, Nishimura S, Huang L. Subacute hypersensitivity pneumonitis in an HIV infected patient receiving antiretroviral therapy. Thorax 2000;55: $625-7$.

63 Gérard Y, Maulin L, Yazdanpanah Y, et al. Sympomatic hyperlactataemia: an emerging complication of antiretroviral therapy. AIDS 2000:14:2723-30.

64 Hetherington S, Steel H, Naderer O, et al. Hypersensitivity reactions during therapy with abacavir: analysis of 636 cases for clinical presentation and risk factors. 7th Conference on Retroviruses and Opportunistic Infections, San Francisco, 2000.

65 Escaut L, Liotier J, Albengres E, et al. Abacavir rechallenge has to be avoided in case of hypersensitivity reaction. AIDS 1999;13:1419-20.

66 Havlir D, Barnes P. Tuberculosis in patients with human immunodeficiency virus infection. N Engl f Med 1999;340:367-73.

67 Pozniak A, Miller R, Ormerod L. The treatment of tuberculosis in HIV-infected persons. AIDS 1999;13:435-45.

68 Narita M, Stambaugh J, Hollender E, et al. Use of rifabutin with protease inhibitors for human immunodeficiency virus-infected patients with tuberculosis. Clin Infect Dis 2000;30:779-83. 